\title{
SIGNIFICADOS ATRIBUÍDOS POR JOVENS ÀS EXPERIÊNCIAS EDUCATIVAS VIVENCIADAS NO PROGRAMA FICA VIVO!
}

\author{
ANA LÍDIA CRISTO DIAS' \\ ORCID: https://orcid.org/0000-0001-9195-1095 \\ MARIA CELESTE REIS FERNANDES DE SOUZA \\ ORCID: https://orcid.org/0000-0001-6955-5854
}

I Universidade Vale do Rio Doce, Governador Valadares, MG, Brasil

RESUMO: Este artigo apresenta resultados de uma pesquisa que buscou compreender a constituição das experiências de jovens de 18 a 24 anos, que participam das atividades no Programa Fica Vivo!, na cidade de Governador Valadares, Minas Gerais. O estudo assume como perspectiva teórica estudos do campo da Sociologia da Juventude e dos Estudos Territoriais. Os dados foram coletados por meio de questionário e entrevistas, e, para a análise, buscou-se o conceito de mobilização de Bernard Charlot. Os resultados apontam significados atribuídos pelos(as) jovens às experiências vivenciadas nesse Programa, relações com o trabalho e com o mundo da cultura, destacando-se, nesse processo, a presença dos(as) oficineiros(as). Conclui-se que o Programa tem cumprido a função protetiva naquele território, além de propiciar experiências educativas ali desenvolvidas, aprendizagens que se revestem de significados para esses(as) jovens, ampliando o acesso à cultura, ao lazer e à cidade.

Palavras-chave: Fica Vivo!. Juventude. Território.

Ana Lídia C. Dias - Mestre em Gestão Integrada do Território pela Universidade Vale do Rio Doce (UNIVALE). Atua em programas e projetos sociais com consultoria e gestão. Grupo de Pesquisa: Núcleo Interdisciplinar de Educação, Saúde e Direitos - UNIVALE. E:mail:< diasanalidia@hotmail.com> .

Maria Celeste R. F. de Souza - Doutora em Educação pela Universidade Federal de Minas Gerais (UFMG). Docente do Programa de Pós-Graduação Stricto Sensu em Gestão Integrada do Território Universidade Vale do Rio Doce (UNIVALE). Grupo de Pesquisa: Núcleo Interdisciplinar de Educação, Saúde e Direitos UNIVALE. E:mail:<celeste.br@gmail.com>. 


\section{MEANINGS ATTRIBUTED BY YOUNG PEOPLE TO THE EDUCATIONAL EXPERIENCES LIVED IN THE FICA VIVO! PROGRAM}

ABSTRACT:This article presents results of a research that sought to understand the constitution of the youth experiences in the Fica Vivo! Program, of young people from 18 to 24 years old who participate in the activities of the Program, in the city of Governador Valadares, Minas Gerais. The study assumes, as theoretical perspective, studies in the field of youth sociology and territorial studies. The data were collected through questionnaires and interviews, and for the analysis, we sought the concept of mobilization by Bernard Charlot. The results point out meanings attributed by the young people to the experiences lived in this Program, relations with work and with the world of culture, highlighting, in this process, the presence of the program workers. It is concluded that the Program has fulfilled the protective function in that territory, in addition to providing educational experiences developed there, learning that are meaningful for these young people, increasing access to culture, leisure and the city.

Keywords: Fica Vivo!. Youth. Territory.

\section{INTRODUĈ̣̃O}

Este artigo tem como cenário de preocupações a correlação que se se estabelece entre juventude e violência, e que alcança de modo significativo os jovens em situação de vulnerabilidade social, quer na condição de agentes, quer majoritariamente na situação de vítimas, como diferentes estudos têm problematizado e denunciado. Com efeito, no meio urbano, os maiores índices de violência abrangem o público juvenil. As pesquisas apontam que a violência envolvendo jovens perpassa por tiroteios, consumo e tráfico de drogas, assaltos, abordagem policial, abuso sexual, discriminação e crimes contra o patrimônio (CARA, GAUTO, 2007; WAISELFISZ, 2013a, 2013b, 2014, 2015, 2016). Nesse cenário de preocupações, destacam-se os homicídios contra os jovens.

Por exemplo, o "Atlas da Violência" (CERQUEIRA et al., 2018) aponta que as maiores vítimas de homicídios são jovens negros que se encontram em territórios com alta vulnerabilidade à violência. Jovens negros também são maioria em cumprimento de penas em sistemas prisionais, além de serem os que mais sofrem violência policial. Gomes e Laborne (2018, p. 6) denunciam o demarcador da raça e 
o racismo presente na sociedade brasileira como determinantes na violência contra os jovens negros: "ser negro é determinante para que a violência incida com mais força sobre essa parcela da população".

Recortamos, nesse contexto, o município de Governador Valadares, que tem comparecido, de modo recorrente, nas pesquisas que apresentam e analisam indicadores da violência no Brasil, com prevalência de taxa de crescimento de homicídios, principalmente no que se refere à violência juvenil (CERQUEIRA et al., 2017; MELO; CANO, 2012; WAISELFISZ, 2013 a, 2013 b, 2014, 2015, 2016).

É sobre esse cenário que este artigo se debruça, e intencionalmente nos interessamos por jovens desse município que vivem em um bairro periférico com altos índices de violência e criminalidade, e que participam do Programa de Controle de Homicídios - Fica Vivo! ${ }^{1}$ (FV!). Compartilhamos neste texto resultados de uma pesquisa qualitativa ${ }^{2}$ que buscou compreender as experiências educativas de jovens que participam desse Programa. O estudo envolveu jovens de 18 a 24 anos, faixa etária escolhida intencionalmente, por considerarmos que eles têm uma maior trajetória no Programa Fica Vivo!, e por se manterem vivos em territórios de vulnerabilidade, cumprindo, assim, os propósitos para os quais o Programa foi gestado.

A pesquisa, realizada em uma abordagem interdisciplinar, coloca em diálogo autores da Sociologia da Juventude e dos Estudos Territoriais, na tentativa de captar a dinamicidade das relações entre os jovens e o território, e que se encontram imbricadas nos modos de ser jovem em situação de vulnerabilidade e nas suas experiências educativas vivenciadas no Programa Fica Vivo!.

\section{APORTES TEÓRICOS: JUVENTUDES E TERRITÓRIOS}

Abordar a temática da juventude e a pluralização do termo “juventudes" é adentrar em um debate em torno do qual há, pelo menos, três aspectos consensuais: "O enfraquecimento da fronteira entre juventude e idade adulta, a individualização dos valores pelos jovens e a necessidade de raciocinar ao mesmo tempo em termos de juventudes, no plural, e de juventude, no singular" (CHARLOT, 2007, p. 203, grifos do autor).

Nessa perspectiva, o autor afirma a importância de se analisar a juventude como condição e as diferentes interpretações dessa condição compondo o mosaico Juventudes. É nesse mosaico que 
se busca compreender a condição juvenil que "refere-se ao modo como uma sociedade constitui e atribui significado a essa condição, sua representação, e à forma como a situação é vivida no conjunto de realidades na sociedade, a condição social" (DAYRELL; PAULA, 2011, p. 34). Se a condição juvenil pode ser entendida a partir do que os(as) jovens vêm construindo como experiências, mediante um contexto sociocultural mais amplo, é preciso considerar que nessa condição se engendram os modos nos quais a situação juvenil é vivida e que se revelam nas distintas experiências juvenis (CHARLOT, 2001; DAYREL, 2003, 2016; PERALVA, 1997).

Nesse debate emerge a compreensão do jovem como sujeito ao mesmo tempo singular e social (CHARLOT, 2001; DAYRELL, 2003). Charlot (2006, p. 16, grifos do autor) afirma que "do ponto de vista empírico e descritivo, não se encontra 'a juventude', encontram-se 'jovens"' que se auto-organizam em grupos, sejam eles de RAP, torcidas, dentre outros, com recortes de gênero, de classe, de raça, geracionais, de lugar, etc., revelando distintos modos de ser jovem (DAYRELL, 2003).

Dayrell e Paula (2011, p. 37) argumentam que "na realidade, não há tanto uma juventude e sim jovens, enquanto sujeitos que a experimentam e sentem segundo determinado contexto sociocultural onde se inserem". Portanto, no cotidiano e nas pesquisas sobre juventude encontram-se jovens que experienciam diferentes modos de vida, sob determinadas condições históricas e sociais. Logo, nas problematizações sobre juventude, deve-se levar em conta a percepção e o conhecimento da realidade do(a) jovem, além da compreensão das distintas formas como ele(a) constrói os significados que atribui às suas experiências.

É nesse sentido que buscamos evitar uma compreensão sobre juventude muito presente no imaginário social como transitória, um tempo de passagem, portanto, do jovem como um "vir a ser" (DAYRELL, 2003, 2016). Com isso, ignora-se a possibilidade de formação do jovem no presente vivido.

O olhar que empreendemos sobre os jovens que participaram deste estudo se sustenta nesse debate teórico sobre juventude e nos mobiliza também a refletir sobre os territórios nos quais eles (elas) transitam e imprimem suas marcas. Portanto,

pensar o tema territórios e juventudes exige pensar a maneira como os jovens constroem e dão significado aos espaços, através dos locais que frequentam, dos estilos de vida, da produção de culturas juvenis, dos padrões de consumo, das relações e da sociabilidade. Exige também pensar de que forma os espaços vividos, construídos e (re)significados pelos jovens influenciam suas escolhas e seus modos de vida. (ALVES; OLIVEIRA, 2014, p. 18)

Ao tratar das experiências juvenis, faz-se necessário defender o território como construído socialmente pelos sujeitos em suas 
relações entre indivíduos e grupos, que evidenciam interesses, conflitos e relações de poder, o que nos aproxima de autores que tematizam território, como Haesbaert (2007). Para o autor a palavra "território" está ligada etimologicamente a terra-territorium e relacionada a térreo-territor (terror, aterrorizar) e vincula-se, assim, ao conceito de dominação (jurídico-política) da terra, em que uns se apropriavam dela e outros nela eram proibidos de entrar. Território, pois, está sempre associado ao poder. Poder num sentido mais amplo (simbólico), para além do poder político (dominação).

Entendemos, então, que o território envolve relações de dominação (poder material) e/ou apropriação (poder simbólico). As abordagens conceituais de território são organizadas em três vertentes básicas:

Dimensão político-jurídica: território como espaço delimitado controlado sobre/por meio do qual se exerce um determinado poder, especialmente o de caráter estatal.

Dimensão cultural(ista): território como produto fundamentalmente da apropriação do espaço feita através do imaginário e/ou da identidade social.

Dimensão econômica (muitas vezes economicista) minoritária: (des)territorialização é vista como produto espacial do embate entre classes sociais e da relação capitaltrabalho (HAESBAERT, 2007, p. 45)

Em nosso estudo, assumimos a dimensão culturalista do território. É a partir do olhar do território como simbólico e cultural que é possível compreender como os sujeitos organizam o espaço, se organizam nele e dão sentido às suas vivências, moldando-o a partir de controles simbólicos.

O território, na vertente aqui enfatizada, tem uma dimensão que vai além da materialidade, pois se constitui pelos grupos e pelas relações. Logo, o território se revela à medida que se vive nele e conforme se vive nele. Ou seja, é o sentido que cada grupo atribui ao seu espaço vivencial, com suas possibilidades e restrições. Sua constituição se relaciona, pois, ao sujeito em sua relação com o outro (no coletivo) e com o lugar em si (objetos, limites geográficos, paisagens, equipamentos sociais, formas de vida, condições habitacionais, acesso a direitos, etc.).

Podemos, pois, falar da imbricação território e territorialidade, posto que esta

efetiva-se em todas as nossas relações cotidianas, ou melhor, ela corresponde às nossas relações sociais cotidianas em tramas, no trabalho, na família, na rua, na praça, na igreja, no trem, na rodoviária, enfim, na cidade-urbano, no ruralagrário e nas relações urbano-rurais de maneira múltipla e híbrida. (SAQUET; SPOSITO, 2008, p. 90) 
Haesbaert (2007, 2008, 2014), em seus debates sobre território, apresenta-nos uma leitura que contribui para compreendê-lo de modo mais abrangente, na qual se pode vislumbrar, por um lado, as possibilidades de ações dos sujeitos nos territórios, em apropriações simbólicas e culturais; e, por outro, precarização, reclusão e exclusão territorial, ou confinamentos, gerados "pela condição de insegurança e descontrole territorial” (HAESBAERT, 2008, p. 18). Conforme argumenta o autor, ao discutir território, deve-se considerar a multiplicidade dele e as territorialidades engendradas nos modos de apropriação espacial de pessoas e grupos.

A relação dessa abordagem com a situação juvenil é a identificação dos múltiplos territórios que os jovens vivenciam, usam, transitam ou criam - a escola, o mundo do trabalho e o mundo da cultura, que indicam diferentes territorialidades vivenciadas pelos jovens através dos movimentos que empreendem e das lutas que travam. Afinal, o território se configura nas múltiplas relações de poder material e de poder simbólico, e são essas relações que o moldam.

Compreendendo que os sujeitos dão vida ao território, mesmo nas contingências, a partir de suas culturas, identidades, vivências, distintas visões de mundo, modos de ser e estar, é que assumimos o Programa Fica Vivo! como um território e buscamos compreender como os jovens nele se territorializam, e como significam a sua experiência ali vivida.

\section{O PROGRAMA FICA VIVO! E OS JOVENS}

O Fica Vivo! (FV!) é um dos quatro programas da Política de Prevenção Social à Criminalidade do Estado de Minas Gerais, gerida pela Secretaria de Estado de Segurança Pública (SESP), que se propõe a pensar a segurança pública como uma política social que investe na qualidade de vida das pessoas. O FV! tem como intuito prevenir e reduzir os homicídios dolosos de adolescentes e jovens, entre 12 e 24 anos, moradores de áreas onde esses crimes se concentram.

O Programa Fica Vivo! se organiza em dois eixos: o da Proteção Social e o da Intervenção Estratégica. O primeiro eixo é composto de Oficinas de Esporte, Cultura e Arte; Análise da Dinâmica Social das Violências e da Criminalidade; Jovens Multiplicadores; Atendimentos Individuais; Projetos Locais, de Circulação e (Inter)Institucionais; Fóruns Comunitários. Já o segundo, pela operacionalização de Policiamento Preventivo Especializado e a formação e o funcionamento de Grupos de Intervenção Estratégica (GIE) (MINAS GERAIS, 2016a). 
Documentos que orientam a organização do trabalho no Programa (MINAS GERAIS, 2009, 2015, 2016a), no que tange ao primeiro eixo, estabelecem que, na oferta das Oficinas de Esporte, Cultura e Arte, se acolha a demanda dos(as) jovens e que elas sejam ministradas por oficineiros(as) preferencialmente residentes na área de abrangência do Centro de Prevenção à Criminalidade (CPC). ${ }^{3}$ Esse critério de escolha dos(as) oficineiros(as) visa contribuir para a Análise da Dinâmica Social das Violências e da Criminalidade no território, reflexão essa que, segundo os documentos citados anteriormente, deve acontecer periodicamente entre os membros da equipe de trabalho, e também podem-se incluir órgãos e instituições parceiras, bem como moradores(as) dos bairros onde se situa o CPC, incorporando jovens que participam das oficinas.

A equipe de trabalho pode se aproximar dos(as) jovens que participam das oficinas tanto de modo individual, mediante os Atendimentos Individuais, quanto de modo coletivo, via Projetos Locais (realizados no bairro em que o(a) jovem mora, de Circulação (desenvolvido fora do bairro de sua moradia) e (Inter)Institucionais; além dos Fóruns Comunitários. Os documentos orientadores do programa destacam a importância da participação juvenil, do diálogo com os(as) jovens na proposição de atividades, da escuta das suas demandas e afirmam que o programa pretende ser "um espaço de construção e diálogo de afirmação do jovem na cidade” (MINAS GERAIS, 2009, p. 76).

O segundo eixo, por sua vez, abarca diretamente os órgãos de segurança pública. A parceria com o Grupo Especializado em Policiamento de Áreas de Risco (GEPAR) da Polícia Militar de Minas Gerais (PMMG) possibilita diálogo, bem como atividades conjuntas entre equipe de trabalho do FV!, polícia, moradores(as), jovens e outras instituições. O Grupo de Intervenção Estratégica (GIE) é composto por representantes de órgãos públicos de diferentes esferas, que se reúnem bimestralmente, com intuito de também dialogar e planejar coletivamente intervenções sobre a Análise da Dinâmica Social das Violências e da Criminalidade (MINAS GERAIS, 2009, 2016b).

Em Governador Valadares, o FV! é desenvolvido em dois CPC de base local, um no bairro Turmalina e outro no bairro Santa Helena. Neste estudo, selecionamos o CPC Turmalina, por ser o primeiro instituído em Governador Valadares, em 2006 (MINAS GERAIS, 2009).

A inserção no campo de pesquisa, após permissão concedida pela Subsecretaria de Políticas de Prevenção à Criminalidade (SUPEC), via diretoria do FV!, contemplou os meses de maio de 2017 a novembro de 2017 e obedeceu às seguintes etapas: acesso e leitura 
de documentos para compreender o funcionamento do Fica Vivo!, de modo geral, e do CPC Turmalina (relatórios elaborados pela equipe técnica do Programa, listas de presenças com a frequência mensal dos jovens às oficinas e relatórios mensais sobre o funcionamento do Programa). Visando a uma aproximação com os(as) jovens, foram acompanhadas oficinas de Futsal, Handebol, Manicure e Pedicure; Projeto Local voltado para o uso do espaço público ${ }^{4}$ e Projeto de Circulação ${ }^{5}$ na cidade, com saídas do bairro.

No período da pesquisa, participavam das ações do Programa no bairro, conforme documentos disponíveis no CPC, cerca de 400 adolescentes e jovens com idades entre 12 e 24 anos. Para este estudo, como já afirmamos, selecionamos jovens com idades entre 18 e 24 anos por, supostamente, terem uma maior trajetória no Programa, e por contradizerem as estatísticas brasileiras que apontam que grande parte dos jovens, de 20 municípios brasileiros, incluindo Governador Valadares, serão "vítimas de homicídio antes de alcançarem os 19 anos de idade" (MELO; CANO, 2012, p. 23).

Foram identificados 30 jovens - 26 homens e 04 mulheres , todos moradores do bairro Turmalina - e que participavam, há mais de três anos, de diferentes oficinas geridas pelo CPC Turmalina. Para levantarmos o perfil social desses jovens, foi preenchido um questionário respondido por eles com informações relativas a idade, escolaridade, sexo e situação no mercado de trabalho, que foram sintetizadas nos quadros 1 e 2 :

QUADRO 1. Levantamento do perfil dos (as) jovens

\begin{tabular}{|l|l|l|}
\hline \multicolumn{3}{|c|}{ Levantamento do perfil dos(as) jovens } \\
\hline \multirow{4}{*}{ Sexo } & Feminino & 04 jovens \\
\cline { 2 - 3 } & Masculino & 26 jovens \\
\hline \multirow{4}{*}{ Idade } & 18 e 19 anos & 10 jovens \\
\cline { 2 - 3 } & 20 e 21 anos & 09 jovens \\
\cline { 2 - 3 } & 22 e 23 anos & 07 jovens \\
\cline { 2 - 3 } & 24 anos & 04 jovens \\
\hline \multirow{5}{*}{ Escolaridade } & Analfabeto & 01 jovem \\
\cline { 2 - 3 } & Ens. Fundamental Incompleto & 05 jovens \\
\cline { 2 - 3 } & Ens. Fundamental Completo & 04 jovens \\
\cline { 2 - 3 } & Ens. Médio Incompleto & 11 jovens \\
\cline { 2 - 3 } & Ens. Médio Completo & 07 jovens \\
\cline { 2 - 3 } & Ens. Superior Incompleto & 02 jovens \\
\hline
\end{tabular}

Fonte: Dados da pesquisa de campo 
Conforme os dados, no que tange ao sexo, há uma prevalência de jovens do sexo masculino; e, no tocante à idade, predominam jovens entre 21 e 22 anos. A maior participação masculina no Programa pode ser compreendida pelos dados relativos à violência juvenil - as mulheres se veem mais na condição de vítimas do que de agentes (CERQUEIRA et al., 2018).

Com relação à escolaridade, apesar de os dados apresentarem prevalência de jovens que cursam o Ensino Médio, se cruzarmos os dados (idade e escolaridade), podemos constatar um acentuado índice de distorção idade/série, como se configura no cenário nacional (INEP, 2017). Não foi objeto de discussão neste estudo a trajetória escolar desses jovens, o que inviabiliza análises mais acuradas desse aspecto. Entretanto, a inserção no campo de pesquisa, a aproximação com os(as) jovens e o que se encontra posto em outros estudos permitem inferências, com relação: a essa distorção sobre a qual incide a vulnerabilidade social; às desigualdades entre territórios, quanto ao acesso da população a equipamentos de lazer e a bens culturais; à maior adequação idade-série das mulheres, situação vivenciada pelas jovens deste estudo; às desigualdades no acesso e na permanência entre negros e brancos; e à vulnerabilidade juvenil marcada pela violência (UFMG, 2013; GOMES; LABORNE, 2018; PNUD; IPEA; FJP, 2017).

Com relação ao trabalho, 27 jovens afirmaram ter experiências no mercado de trabalho, e pudemos constatar que elas são diversificadas e voltadas para a prestação de serviços, como se pode conferir no quadro 2: 
QUADRO 2. Situação dos(as) Jovens no Mercado de Trabalho

\begin{tabular}{|c|c|c|}
\hline \multicolumn{3}{|c|}{ Situação dos (as) Jovens no Mercado de Trabalho } \\
\hline \multirow{2}{*}{$\begin{array}{c}\text { Experiência no } \\
\text { mercado de trabalho }\end{array}$} & Não têm experiência & 03 jovens \\
\hline & Têm experiência & 27 jovens \\
\hline \multirow{21}{*}{$\begin{array}{l}\text { Detalhamento das } \\
\text { experiências }\end{array}$} & Pedreiro & 05 jovens \\
\hline & Auxiliar de Escritório & 02 jovens \\
\hline & Serralheiro & 02 jovens \\
\hline & Auxiliar de Lanchonete & 01 jovem \\
\hline & Ajudante de Pedreiro & 01 jovem \\
\hline & Ajudante Geral de Solo Sondagem & 01 jovem \\
\hline & Caixa de Supermercado & 01 jovem \\
\hline & Cozinheira & 01 jovem \\
\hline & Eletricista & 01 jovem \\
\hline & Entregador de Água & 01 jovem \\
\hline & Instalador de Andaimes & 01 jovem \\
\hline & Repositor de Mercadorias & 01 jovem \\
\hline & Soldador & 01 jovem \\
\hline & Vendedor & 01 jovem \\
\hline & Operador (a) de Telemarketing & 01 jovem \\
\hline & Padaria & 01 jovem \\
\hline & Auxiliar de Mecânica & 01 jovem \\
\hline & Moto-Táxi & 01 jovem \\
\hline & Empresa de Limpeza Urbana & 01 jovem \\
\hline & Panfletagem & 01 jovem \\
\hline & Empresa de Transporte & 01 jovem \\
\hline
\end{tabular}

Fonte: Dados da pesquisa de campo

Os dados evidenciam que para esses (as) jovens, a relação com o trabalho é marcada pela precariedade, envolvendo bicos e informalidade, o que também se revela em outros estudos sobre juventude e trabalho, como discutiremos na próxima seção deste artigo (ABRAMOVAY; CASTRO; WAISELFISZ, 2015; CASTRO; ABRAMOVAY, 2002; CORROCHANO, 2014; SPOSITO, 1993). 
Se até aqui apresentamos um panorama geral dos jovens no Fica Vivo!, no qual podemos ler algumas regularidades do perfil desse grupo, para tratar das experiências específicas dos jovens - a "significatividade", como nos propõe Charlot (2009) -, e refletindo sobre os distintos modos de ser jovem, buscamos captar, por meio de entrevistas, os significados que os jovens atribuem à experiência educativa nesse programa.

Para isso convidamos os(as) 30 jovens para participarem de uma entrevista e obtivemos resposta positiva de 07 deles ( 05 homens e 02 mulheres). Desse grupo, 03 homens abandonaram a escola nos últimos anos do Ensino Fundamental; 01 homem concluiu o Ensino Médio e mais 01 abandonou a escola no Ensino Médio; as 02 mulheres cursavam o Ensino Médio. Vale salientar uma prevalência de jovens negros entrevistados, pois somente um homem, dos 07 jovens, é branco. ${ }^{6}$

Para nossa análise, buscamos em Bernard Charlot as discussões sobre mobilização. Para o autor, "mobilizar-se é pôr-se em movimento" (CHARLOT, 2000, p. 54). O sujeito se mobiliza para aquilo que faz sentido para ele, "porque existem boas razões para fazê-lo" (p. 55). Mobilizar-se supõe a atividade do sujeito, que possui, portanto, "uma dinâmica interna" (p. 55) cujas referências ele encontra em sua história pessoal e social, que guarda relações de sentido com aquele momento particular de sua vida ou com um futuro que projeta para si mesmo (CHARLOT, 2000, 2009).

Buscamos, pois, nos textos transcritos das entrevistas, o que mobilizava os(as) jovens para participarem das ações do Fica Vivo!, posto que frequentar ou não o Programa é uma opção pessoal, não é obrigatória, e estar matriculado em uma escola também não é condição para a frequência ao Programa, conforme regulamentado (MINAS GERAIS, 2009).

A escuta desses jovens possibilitou identificar o estabelecimento de relações significativas entre o trabalho e a cultura que atravessam as experiências educativas vivenciadas por eles e por elas em o Fica Vivo!; e apreender o que eles e elas relatavam como aprendizagens no Programa.

\section{RELAC̣̃̃ES COM O TRABALHO}

Para os(as) jovens entrevistados(as), a experiência no Fica Vivo! é significativa porque, de algum modo, os(as) aproxima da questão do trabalho que, assim como para outros jovens, se coloca nas intrincadas relações entre escola e trabalho, ora como causa apontada para o "deixar a escola" (Antônio, ${ }^{7} 22$ anos, há três anos no Fica Vivo!), ora para a correlação que se estabelece entre escolaridade e qualificação para o trabalho. 
Além de Antônio, quatro dos sete jovens entrevistados interromperam a trajetória escolar pela escolha que tiveram que fazer entre escola e trabalho, como relatam Wagner e Augusto: "Porque eu comecei a trabalhar com 15 anos, aí o horário não batia, aí eu preferi o emprego do que a escola" (Wagner, 20 anos, há 03 anos no Fica Vivo!). "Dei uma parada de bobeira mesmo [...] Bobeira mesmo, negócio de trenzinho viajando pra lá e pra cá, dei uma parada, você sabe que trenzinho viaja, né?" (Augusto, 18 anos, há três anos no Fica Vivo!).

Ecoa na fala desses jovens o que já se evidenciou em outros estudos sobre o abandono escolar em função da necessidade de ingressar precocemente no mercado trabalho, cujas condições inviabilizam a frequência à escola (ANDRADE; FARAH NETO, 2007; CORROCHANO, 2014; UFMG, 2013).

Com efeito, o trabalho é uma faceta importante da condição juvenil (CHARLOT, 2006; CORROCHANO, 2014; DAYRELL; CARVALHO; GÉBER 2012; LEÃO; NONATO, 2014) e possibilita aos jovens autonomia, reconhecimento da sociedade, acesso ao lazer e a bens de consumo - tais como roupas, tênis, eletrônicos, dentre outros -, bem como a passagem para a vida adulta. Vale salientar que há ainda os jovens que trabalham porque precisam contribuir com a renda familiar, o que é muito presente na vida dos jovens em territórios de vulnerabilidade (LEÃO; NONATO, 2014).

É nesse sentido que podemos compreender a opção dos jovens entrevistados pelo trabalho em detrimento da escola e como tema recorrente nas entrevistas de todo o grupo: "Para muitos jovens, o trabalho se apresenta como um dos principais temas de interesse para sua vida, para sua identidade, como um direito importante para sua cidadania e, principalmente, como uma necessidade para obtenção de recursos financeiros" (ABRAMOVAY; CASTRO; WAISELFISZ, 2015, p. 39).

Nos dados coletados sobressai o desejo dos(as) jovens de conseguir inserção no mercado de trabalho: “...en quero arrumar um emprego porque tá ruim pra viver só de futebol, né?" (Wagner). "Tô à espera, correndo atrás, entregando currículo, mas que um dia vai dar certo" (Augusto). "Coloquei curriculo ontem, agora é esperar chamar" (Talita, 18 anos, há 10 anos no Fica Vivo!).

Os jovens buscam, pois, sair da condição de desempregados. Se "...o desemprego é uma experiência comum para muitos jovens" (LEÃO; NONATO, 2014, p. 17), ele é vivenciado pelos(as) jovens de acordo com as condições sociais (origem social, sexo, raça, escolaridade), o que repercute também na situação dos(as) jovens do Fica Vivo!.

Nas entrevistas, eles e elas se mostram preocupados em conseguir um emprego, e Antônio argumenta sobre o momento 
econômico do País, com a retração do emprego: "Agora nessa crise tá difícil caçar emprego" (Antônio).

A essa "crise" apresentada por Antônio, pode se acrescentar que o fato de serem jovens moradores de um bairro sobre o qual pesam os índices de violência, agregado ao fator raça, força-nos a refletir sobre "a segregação racial nos territórios" (GOMES; LABORNE, 2018, p. 14), que se configura também como dificultadora do acesso ao trabalho. As territorialidades desses jovens são constituídas, pois, nas contingências da vida naquele território, marcadas fortemente pela exclusão escolar (a necessidade do trabalho em detrimento da escola), pela dificuldade de acesso ao trabalho e pela precarização socioespacial decorrente da violência e da criminalidade que os leva a viver "situações de profunda insegurança e imprevisibilidade" (HAESBAERT, 2014, p. 189).

Corrochano (2014, p. 211, grifos da autora) argumenta que “...a realidade da maioria dos jovens [...] no mercado de trabalho brasileiro sempre esteve muito mais próxima da instabilidade e das idas e vindas e de um constante se virar para conseguir ganhar a vida", e é nesse sentido que os(as) entrevistados(as) "se viram": (Augusto).

Vivendo, pois, nesse território de vulnerabilidade, o trabalho dos jovens do FV! do CPC Turmalina não é o que eles desejam, mas o que é necessário e oportuno. Por isso, diante do desemprego, eles buscam estratégias de geração de renda e trabalho via "bicos" (LEÃO; NONATO, 2014).

Os dados coletados mostram essa proximidade dos jovens com os "bicos" como opção de geração de renda na situação da ausência do trabalho: "Quando a gente faz. um biquinho aí e consegue um trocado [...] o que aparece, né, a gente não escolhe, não [...]. Não tá podendo escolher, ué" (Wagner). "Procurar, procuro, né, porque de vez, em quando, igual tempo de chuva é difícil arrumar serviço, aí meu patrão me chama eu de vez. em quando, ai aparece bico e outro serviço, aí eu pulo em cima" (Antônio).

Além do "bico", o trabalho informal também comparece na fala dos(as) jovens. O jovem Antônio, por exemplo, trabalha como gesseiro. E, como ele apresenta em seu relato, quando chove, o patrão não o contrata. Na mesma situação, encontra-se o jovem Felipe, que trabalha com o pai como eletricista. No dia que ele nos concedeu a entrevista, por exemplo, só foi possível o encontro porque naquele dia não tinha trabalho, como ele explica durante a entrevista. A jovem Talita também é um exemplo de trabalho informal: ela ajuda a mãe no salão aos finais de semana, fazendo unhas.

Para os(as) jovens deste estudo, a relação com o mundo do trabalho é marcada pela ausência (falta do trabalho), pelos bicos, pelo 
trabalho informal, pelas exclusões como jovens negros(as) e pobres, pelo compartilhamento de tarefas laborais com a família. E nesse cenário que eles(as) aspiram ao trabalho formal, que se insere em seus projetos como significativo para a melhoria das condições de vida. É nessa perspectiva que eles(as) se mobilizam em direção ao Fica Vivo!, como expectativa de que ele favoreça a preparação para entrevistas, a organização de currículos e como possibilidade de atuação profissional em outras experiências com jovens.

Um dos significados encontrados por esses jovens no Fica Vivo é a busca por orientações que possam ajudá-los a se inserir no mercado de trabalho - como se comportar, o que falar e o que vestir em uma entrevista de emprego:

Tem muita dificuldade, sim, tem muita dificuldade no modo de falar porque não tem uma pessoa pra aconselhar ela igual tipo assim, o Fica Vivo!. Teve jovens que chegou perto de mim e falou assim: "Ah, eu vou lá no Fica Vivo! pra eles me instruir o que eu vou falar lá. Como não tinha, eles ficou sem saber o que falar, teve até o "Moranguinho" [...] ele chegou perto de mim e falou: "Eu vou lá no Fica Vivo! saber disso" eu falei: "oh, eu acho que não tá funcionando, não tem data de voltar" aí ele foi pra entrevista e não soube o que falar lá, acabou que não deu certo [...] Porque tem gente aqui, até amigo meu, que vai pra entrevista de brinco, menina vai com o decote caindo, atrapalha bastante, né? (Felipe, 21 anos, há nove anos no Programa)

Essa busca é recorrente para todos os(as) jovens entrevistados(as) que esperam que o Programa os(as) oriente nessa trajetória rumo ao trabalho: "[...] igual antes de morar aqui a Tatiana ${ }^{10}$ mesmo falou que se eu precisasse de um emprego, fazia um currículo, entregava ela que ela ia me ajudar" (Antônio).

No âmbito de dificuldades para os(as) jovens buscarem um emprego, eles argumentam sobre a importância do Programa para ensinar-lhes, ou ajudar, por meio dos(as) analistas na elaboração de um currículo, ou mesmo na indicação de cursos profissionalizantes.

Ingrid destaca o apoio das analistas do Programa tanto na elaboração do currículo quanto na atenção que elas prestam às vagas de trabalho: "na parte do emprego, as meninas [as analistas do Fica Vivo!] vai, far. o curriculo pra mim, fala onde tá precisando e direto elas estão olhando e elas falam com a gente: 'oh, tá tendo vaga em tal e tal lugar', já encaminha pro curso também, já fiz. curso aqui através deles" (Ingrid, 22 anos, há 10 no Fica Vivo!).

Outra alternativa de inserção no mundo do trabalho é a indicação por alguém da família, do seu vínculo social, e espera-se também que a equipe de trabalho do FV! cumpra esse papel:

Minha mãe que me indicou, trabalhava do lado. Viu que tava precisando... [...] Direto eu faço entrevista... mas não dá certo [...] Tem pessoas muito conhecidas [no Fica Vivo!] que pode me indicar. (Wagner) 
Eu trabalhei na $A \ll C$, que eu era atendente e também já, por indicação mesmo do pessoal do Fica Vivo!, inclusive até mesmo do Mauro e a Natália eu tava dando oficina de circo lá na escola no Planalto. (Ingrid)

Nessas falas, a indicação para uma vaga de emprego comparece como uma estratégia de inserção no mercado de trabalho e, embora Wagner e Ingrid não façam referência ao bairro onde moram, ou à discriminação com relação à raça, esses são componentes a refletir nas tentativas de inserção no mercado de trabalho desses(as) jovens, por traduzirem "mecanismos de discriminação [que] estão presentes na busca por trabalho: sexo, cor/raça, ausência de cursos fortes realizados em escolas de renome, aparência física e local de moradia" (CORROCHANO, 2014, p. 216).

Ingrid relata dois encaminhamentos para o mercado de trabalho via Fica Vivo! - atendente de uma empresa de telemarketing e oficineira do Programa Mais Educação ${ }^{11}$ (PME) em uma escola pública, onde ela ministrou oficina de circo.

Assim, para ela, a condição de jovem participante de um programa social, mesmo sendo negra e vivendo em território de vulnerabilidade, contribuiu para a sua inserção no PME. Destaca-se, na participação dos jovens no Programa, a possibilidade de tornar-se jovem Multiplicador, o que pode ter ajudado Ingrid - que relata ter sido multiplicadora - a inserir-se no mercado de trabalho, por ter vivenciado essa experiência. Multiplicador é aquele adolescente ou jovem que mostra habilidade com o ofício (tema da oficina), que tem boa relação com os(as) jovens e que apresenta facilidade em transmitir os objetivos do Programa. Ao atuar junto ao oficineiro(a), abrem-se um canal de diálogo e a troca de saberes, o que contribui para o desenvolvimento da competência argumentativa - $\mathrm{O}(\mathrm{a})$ jovem se torna referência para os demais e assume posição de liderança (MINAS GERAIS, 2009, 2016a). Essas condições foram vividas por Ingrid no Programa e demonstradas nos contatos mantidos com ela no campo de pesquisa.

Talita, também jovem negra, explicita tentativas frustradas de participar dos processos seletivos. Mostra, ainda, uma alternativa por ela usada de usufruir o direito de trabalhar como jovem aprendiz. Mas, ainda assim, não conseguiu vencer as barreiras impostas pelo mercado de trabalho:

Coloquei [currículo] no Coelho Diniæ, Lojas Americanas, lá no Shopping e fizo o negócio lá do antigo... antigo... antigo... ah, esqueci o nome, você preenche lá o nome do negócio, aí eles te indicam pro serviço. [...] Então, Jovem Aprendiz, você na verdade vai trabalhar numa carga horária diferenciada pra dar pra você estudar também pra não atrapalhar seus estudos. Ai você passa alguns dias estudando, fazendo curso [...] Ah, o tanto de currículo que já coloquei e nenbum me chamou. (Talita) 
Corrochano (2014, p. 216) oferece uma possibilidade que nos parece ajudar a compreender a situação narrada por Talita. Segundo a autora, "O tempo de espera por um trabalho [...] é bem maior para jovens pobres e negros”. Esta é, pois, também, a realidade vivida pela jovem Talita, como negra.

Portanto, para esses jovens, mesmo nas vulnerabilidades associadas ao trabalho, o FV! tem se colocado como território significativo de preparação para a inserção no mercado de trabalho, no que se refere à orientação para entrevistas de emprego, à construção de currículos, ou a maior competência argumentativa e de liderança para os(as) jovens que vivenciam a experiência como multiplicadores.

Se a relação juventude, trabalho e escola se mostra atravessada por diferentes tensões e antagonismos que envolvem aspectos da socialização juvenil, da qualificação e do diploma, do desemprego e do trabalho precário, do direito à escola e da necessidade de sobrevivência, do trabalho diurno e do ensino noturno, dos "bicos", etc., como nos mostram os autores já citados e que se voltam para estudos sobre essa dimensão na vida dos jovens, tais tensões se veem acirradas, para os jovens do Fica Vivo!, pelo fator território, no qual se entrecruzam a vulnerabilidade e a raça, forjando suas territorialidades juvenis.

\section{RELAÇÕES COM O MUNDO DA CULTURA}

$\mathrm{Na}$ literatura sobre juventude, o mundo da cultura tem comparecido como parte significativa da condição juvenil, por possibilitar ao jovem expressar, a partir de códigos, suas representações e seus referenciais simbólicos e culturais. O RAP, o Hip Hop, o Funk e o Graffiti, por exemplo, se apresentam em diferentes estudos sobre a relação entre jovens e cultura, por meio dos quais os(as) jovens fazem uma releitura do social, vivenciam práticas de sociabilidade, constroem e portam símbolos (cortes de cabelo, roupas, bijuterias, linguagens etc.), demarcam lugares, denunciam situações de discriminação, de violência e desigualdade social, tecem críticas e apresentam suas expectativas como jovens (DAYRELL, 2003; SPOSITO, 1993).

As marcas desse mundo da cultura foram visíveis durante a coleta de dados nos modos de vestir dos(as) jovens - com camisetas, bonés, brincos, tatuagens identificadoras de pertencimento a diferentes grupos -; no compartilhamento de letras de música e dos estilos musicais; nos gingados e danças; nos códigos linguísticos que marcam as territorialidades juvenis, definindo modos de apropriação do território que cerceiam a entrada de outros atores nesse território - oficineiros(as), analistas e pesquisadoras. 
Embora visíveis no cotidiano desses(as) jovens os gostos, estilos musicais e de dança não são objeto das Oficinas, e constatase uma prevalência de participação dos(as) jovens nas Oficinas de Esporte (Handebol, Futsal e Basquete).

É importante destacar que, apesar de esses temas não prevalecerem na temática das Oficinas, eles são trazidos pelos sujeitos nos seus modos de ser e estar. Além disso, os documentos norteadores do FV! destacam a importância de os(as) oficineiros(as) aproveitarem os "nichos abertos" pelos(as) jovens e suas culturas para desencadear discussões e elaboração de propostas (oficinas e projetos) a partir das demandas apresentadas por eles(as) (MINAS GERAIS, 2009, 2016a).

O Graffiti, como componente da cultura juvenil, é marca constante no bairro, como foi possível constatar na inserção no campo de pesquisa, e foi possível acompanhar os(as) jovens em uma das atividades do Projeto Local, já citado. Como "[...] forma visual de ocupação do espaço urbano" (SPOSITO, 1993, p. 169), pelo Graffiti, os jovens se manifestaram nos posicionamentos na defesa do bairro (limpeza, saúde, valoração da paz).

Viana (2014, p. 251), ao discutir artes e culturas juvenis no Ensino Médio, compreende cultura como “...um campo mais amplo e diz respeito a um conjunto de elementos materiais e simbólicos historicamente construídos que conferem identidade a um determinado grupo social ou sociedade”. Partindo dessa ótica, argumentamos que as atividades de esporte e lazer compõem, nesta análise, o mundo da cultura, por serem marcadas pelas escolhas dos(as) jovens por essas Oficinas.

O esporte é a modalidade mais acessada pelos jovens do FV!. Os dados coletados mostram que Futsal, Handebol e Basquete são as oficinas mais frequentadas pelos(as) jovens pesquisados(as). Segundo Viana (2014, p. 256), nos esportes “...podemos achar simbologias e significados que podem ser expandidos, cruzados com outras experiências...”. Para a autora, essas manifestações abarcam elementos culturais e possuem linguagens e visuais próprios.

Os dados das entrevistas apontam para um amor entre os jovens e o esporte: "É porque eu toda vida sempre amei jogar futebol, né?" (Felipe); "Ah, porque en gosto demais... já gosto muito de futebol mesmo desde pequeno ai" (Wagner); "É, minha área que eu gosto mesmo é a área do esporte...en gosto mesmo... jogo bola, jogo vôlei, jogo handball [...]” (Ingrid).

É a participação nessas oficinas que favorece a eles e elas circular por outros territórios, ao participarem de campeonatos:

São fora do Turmalina, na verdade tem aqui no Turmalina, tem fora, entendeu? E tem gente 
lá do Carapina que comenta muito da oficina daqui, fala que a oficina daqui tem bastante jovens porque aqui eles investem, tipo assim, os professores investe o Turmalina sempre coloca oficina na Copa SESC e tal e eles falam que lá eles sentem falta disso, entendeu? (Ingrid)

Essa oportunidade de os(as) jovens saírem do território por meio dos Projetos de Circulação do FV!, para participar de campeonatos de esporte, possibilita o acesso à cidade via Programa. Santos e Ysayama (2014), ao analisarem as propostas de lazer presentes nos documentos do Programa Fica Vivo! em Minas Gerais, evidenciam o acesso ao lazer como componente importante do Programa, como um direito social dos(as) jovens, e destacam os cuidados que se deve ter para que as oficinas e as propostas envolvendo esporte e lazer não sejam vistas como "salvacionistas", como se, por meio delas, fosse possível reduzir a violência no território. Com efeito, há que se considerar, na constituição dos territórios vulneráveis, as relações de poder, as construções simbólicas e culturais, os códigos e as regras de conduta (da polícia, do narcotráfico, dos próprios moradores), as desigualdades sociais e as contenções que se apresentam nesses aglomerados urbanos (HAESBAERT, 2014).

Os autores destacam a aposta que se faz na oferta dessas oficinas como estratégias que "podem fortalecer a adesão dos jovens às propostas do programa e às novas formas de lidar com a violência, favorecendo a reconstrução de espaços diferenciados de diálogo e administração dos conflitos" (SANTOS; YSAYAMA, 2014, p. 6).

Um aspecto destacado pelos autores é a necessidade de diálogo com os(as) jovens no planejamento dessas ações, valorizando, assim, a condição juvenil. Essa participação pode ser flagrada em diferentes momentos no campo de pesquisa, como: roda de conversas realizadas com os jovens, participação na elaboração e na execução de Projetos Locais e de Circulação, dentre outras atividades.

Cabe destacar que a maioria dos homens entrevistados não frequenta mais a escola, onde talvez pudessem ter acesso ao esporte e ao lazer. Portanto, de modo geral ficam circunscritos ao bairro, pelas dificuldades de acessar o esporte e o lazer em outros espaços da cidade, em razão dos custos com o deslocamento, ou porque não podem "pagar por eles", como os jovens de outros grupos sociais, ou porque têm a circulação em outros bairros cerceada pela violência, como relata Antônio na entrevista sobre o acesso a atividades em outros bairros e no centro da cidade: “...eu frequento só o Turmalina mesmo, porque eu tenho umas tretas, umas guerras também, eu só fico no meu bairro mesmo, aí eu fico mais quieto... difícil eu vim cá, pro centro quando eu vou, vou de moto ou de carro" (Antônio). 
A restrição ao bairro é recorrente em outros relatos: "É meu lazer é ficar em casa e curtir com os amigos” (Wagner); "Ah, eu não gosto de sair não, en gosto de ficar só aqui dentro do bairro mesmo" (Ricardo, 19 anos, há quatro anos no Fica Vivo!). Quando lhes é perguntado por outros espaços em que eles costumam transitar, há uma prevalência de atividades dentro do próprio bairro, dentre as quais se ressaltam conversar com amigos, atividades voltadas para o esporte, ir à igreja e à lanchonete.

Ingrid afirma escolher ir ao Fica Vivo!, porque "às vezes não tinha nada pra fazer, ou ficar em casa jogando vídeo game, ou ficar na rua, pra rua afora, ia à Oficina". Dentre os(as) entrevistados(as) somente ela relata articular ações do mundo da cultura para além do FV!, como participação em campeonatos de esporte em outro bairro: "Jogo [...] de vez. em quando aparece... mas eu tô com um... que eu jogo num time lá na Ilha [...] Foi uma das meninas que jogava junto com a gente. Ela começou a jogar lá aí foi me chamou, ai a gente comecou a participar lá também" (Ingrid).

Assim, as vivências juvenis se circunscrevem àquele território. Desse grupo, somente um jovem e uma jovem dizem sair do bairro. Enquanto o jovem afirma que tem essa prática "de vez em quando", a jovem relata que recentemente foi a primeira vez que ela saiu do bairro:

Costumo, de vez em quando vou pra outros bairros pra distrair porque vê as caras das mesmas pessoas enjoa, né? Dá um passeio, né? (Augusto)

Tipo assim, igual se eu saio do bairro, o único bairro mesmo que eu saio é o Planalto ali. Igual ontem mesmo eu subi na aula de dança; mas, acho que não teve. [...] Mas, subi lá só ontem só, primeira vez: (Talita)

Haesbaert (2007) argumenta sobre uma multiterritorialidade potencial (que são as possibilidades de trânsito do sujeito por diferentes territórios) e uma efetiva (as territorialidades efetivadas pelos sujeitos nesse trânsito). Nessa distinção apresentada pelo autor, ele argumenta a respeito da diferenciação entre a elite e as pessoas que se encontram na base da pirâmide social. Se a elite tem maior poder de escolha sobre os territórios nos quais transita, as pessoas que não pertencem a esse grupo vivem, desde o nascimento, a falta de opção de escolha do seu primeiro território (bairro, rua, habitação etc.). É nesse primeiro território e em tantos outros, por vezes nas mesmas condições materiais, que se constroem diferentes territórios. $\mathrm{O}(\mathrm{A})$ morador(a) é conhecedor dos códigos e das relações de poder da comunidade. Além disso, esse(a) mesmo(a) morador(a), muitas vezes, transita por diferentes territórios do trabalho, um dia é pedreiro, outro é porteiro, outro segurança (HAESBAERT, 2006). 
É, pois, nessa construção e nesse uso diferenciado que se faz do território, que os jovens vivenciam sua situação juvenil e mostram um jeito próprio de ser jovem. Experienciam a situação juvenil em múltiplos territórios, sejam eles a escola, o trabalho, dentre outros. Eles amam, sofrem, posicionam-se, relacionam-se, possuem desejos e projetos de melhorias de vida, divertem-se e pensam/agem a respeito de sua condição de vida; e é nesse contexto de relações e contradições que (re)criam culturas. Para os(as) jovens deste estudo, o Fica Vivo! é um território juvenil, de ampliação do acesso à cultura, esporte e lazer, de encontro com outros jovens.

Além disso, ele se configura como um território protetivo. O FV!, tem sido lugar de aprendizado que faz sentido para a vida e contribui para escolhas que fogem do mundo da violência, tensionando as vulnerabilidades vividas naquele território:

\footnotetext{
Ih...se não fosse o Programa, eu tava que nem muitos jovens aí que cresceu junto comigo, né, a maioria foi pro lado do crime, outros já estão até morto, têm muitos que tá preso, as meninas mesmo já virou mãe, já virou mulher de bandido e eu não, eu tô aqui...não faço nada da vida, mas também não...não fui pro caminho errado, não. (Ingrid)
}

Que tem, tipo assim, tem muitos meninos aí, todo mundo sabe isso não pra ninguém não, que mistura no meio desses meninos aí que gosta de fumar a droga deles, aí tem vez que quando tem oficina eles invés de estar lá fumando, eles tá na oficina, né? Ai distrai a mente, né? Deixa esse trem, essa vida do crime de lado. (Wagner)

O Programa Fica Vivo! se destaca, para os jovens, como lugar que possibilita aprendizagens, e nesse cenário comparece a figura $\operatorname{dos}($ as) oficineiros(as).

Conforme o Guia de Orientação do Fica Vivo! (MINAS GERAIS, 2016a), há duas exigências no que tange ao perfil do(a) oficineiro(a): ${ }^{12}$ ser preferencialmente morador(a) de uma das áreas de abrangência do FV!; e ter experiência com trabalhos voltados para a adolescência e para a juventude.

Os dados coletados nas entrevistas mostram que os(as) jovens têm os(as) oficineiros(as) como referência e destacam: o fato de os(as) oficineiros(as) se mostrarem preocupados(as) com os(as) jovens; as aprendizagens construídas a partir dos ensinamentos dos(as) oficineiros(as); e o incentivo para estudar. Inclusive, os(as) jovens afirmam que, se estão no Programa, é graças ao incentivo dos(as) oficineiros(as), e atribuem a esses profissionais uma mudança positiva na postura interpessoal. Abaixo, selecionamos algumas falas dos jovens que evidenciam esses aspectos: 
É porque eu toda vida sempre amei jogar futebol, né? E o que mais me incentivou a ficar no Programa é pelo fato dos dois professores [oficineiros(as)], tanto pelo Fábio quanto o Bruno, porque eles são duas pessoas assim... porque a gente sumiu do programa uma, duas, três oficinas, eles já procura saber porque a gente não foi, se está acontecendo alguma coisa, procura dar presente pra gente. Igual o Bruno mesmo, sumiu, ele já liga: "aconteceu alguma coisa"?... vai em casa visitar, se tiver passando algum problema, ele dá conselho, comenta pra vir aqui... por ele ser um professor tão bom, fazer aquilo por amor, a gente acaba gostando das coisas [...]. (Felipe)

O que mais me marcou foi o modo de cada um deles [os(as) oficineiros(as)] lidar com os jovens, entendeu? Tem um que... eu acho até bom ressaltar, foi que me ensinou bastante, foi 3 oficineiros. Foi a Natália, a Rebeca e a Isadora. A Isadora foi a minha primeira oficineira e tipo assim, muitas coisas que eu não aprendi em casa, eu fui aprender com ela. Antigamente eu era uma pessoa muito revoltada da vida, brigava demais, tinha muitos problemas na escola e tal, mas dai com o tempo, depois que eu fiquei conhecendo a Isadora, ela foi procurando conhecer mais um pouquinho da minha vida, conversando comigo, ai foi mudando meu jeito de ser... hoje em dia não, boje em dia eu corro de uma briga. (risos) (Ingrid)

Tanto que o Bruno chegou perto de mim e falou assim: gente, vamos estudar que vai fazer falta pra vocês lá na frente; e os meninos escuta muito ele, aí eu vendo isso, vendo que realmente fazia muita falta... eu tenho um cunbado mesmo que ele parou de estudar e não consegue um emprego mesmo de nada, porque sempre pede estudo [...]. (Felipe)

Constatamos que os(as) oficineiros(as) têm ido ao encontro dos(as) jovens, o que tem possibilitado que eles e elas valorizem o FV! como um lugar de aprendizagens; logo, de ações educativas, que podem gerar mudanças significativas na sua vida. A análise dos dados aponta para uma relação de respeito à individualidade do jovem, bem como à reconstrução de seus saberes.

A partir do perfil traçado por Dayrell, Carvalho e Geber (2012) sobre os(as) oficineiros(as)-educadores(as) do PME, é possível estabelecer correlação com os(as) oficineiros(as) do FV!: ser morador(a) do bairro; ser jovem já atendido pelo programa ou projeto em que atua; ter trajetória em movimentos sociais; ser privado(a) de acesso a bens e equipamentos culturais.

O fato de os(as) oficineiros(as) do FV! serem preferencialmente moradores(as) do bairro, em que ministram oficinas, estabelece um vínculo entre jovem e oficineiro(a), o que gera proximidade e compreensão sobre o território que compartilham e favorece a construção de relações de aprendizagem. Em função de muitos desses oficineiros(as) terem sido jovens atendidos por projetos/programas sociais, os vínculos afetivos com os(as) atendidos(as) são fortalecidos, o que contribui para a permanência dos(as) jovens no FV!.

Os(As) oficineiros(as) do FV!, assim como os(as) pesquisados(as) por Dayrell, Carvalho e Geber (2012), também têm uma trajetória em diferentes movimentos sociais, sendo 
possível estabelecer troca de saberes e experiências com os(as) jovens atendidos(as). Apesar dessas experiências significativas em movimentos sociais, o acesso dos(as) oficineiros(as) educadores(as), como moradores desse território a bens e equipamentos culturais, tais como teatros, espetáculos, shows, dentre outros, é também restrito.

Pelo relato dos(as) jovens sobre os(as) oficineiros(as), podemos concluir que a maneira como eles(as) conduzem o trabalho transforma as Oficinas “... não apenas como um ambiente de aprendizagem de um saber; mas sim como um espaço de uma formação humana, de socialização e transmissão de valores..." (DAYRELL; CARVALHO; GÉBER, 2012, p. 165).

A partir da análise dos dados, é possível destacar algumas aprendizagens que os jovens atribuem ao FV!, dentre os quais citamos: lugar de aprender, contribuição para inserção no mercado de trabalho e para tomada de decisões, construção de vínculo com oficineiros(as) e com outras pessoas.

As Oficinas do FV! são fonte de aprendizagem para o jovem Augusto: "Ah, tipo assim, a gente vê eles dançando e dá uma vontade de dançar, aprender, dá vontade de irtambém, a gente vê lá dançando, aí a gente vai, aprende coisa que não sabe, né? Ai aprende com eles [com os (as) oficineiros(as)] (Augusto).

Além disso, as Oficinas do FV! têm contribuído para a inserção no mercado de trabalho, uma vez que os(as) oficineiros(as) se dispõem a auxiliar na construção de um currículo, bem como buscar vagas de trabalho. Para os(as) jovens, os conselhos dos(as) oficineiros(as) interferem na tomada de decisões, o que fortalece a relação entre oficineiro(a) e jovem, como relata Antônio ao recordar o apoio da oficineira para que ele conseguisse trabalho: "ela conversava comigo, me dava conselho altas coisas" (Antônio).

$\mathrm{Um}$ dos relatos nos mostra o sentido do FV! para eles enquanto jovens, os conselhos dos(as) oficineiros(as) para escolhas que se distanciam do mundo das drogas e que se revelam em formas de aprendizagens para a vida: "Euparticipo, né, desde os meus 11 anos, igual en te falei... muita coisa boa, os professores [os(as) oficineiros(as)] ensinando muita coisa, dando exemplos, sempre incentivando a gente a não entrar no mundo das drogas, sempre explicando, sempre vai o pessoal do Fica Vivo! explicar pra gente sobre isso (Felipe). O fato de esse jovem estar participando do Programa há 11 anos também é uma forma de manifestar o valor das aprendizagens ali construídas para sua vida.

Outra jovem destaca o sentido das relações ali geradas e das aprendizagens construídas para a vida: "Ah, é, os laços que a gente acaba criando com os oficineiros com os jovens e aprendizagem que a gente leva pra vida (Ingrid). 
A credibilidade dada pelos(as) jovens às orientações do(a) oficineiro(a) se manifesta na escuta atenta aos conselhos que se concretizam em atitudes e escolhas de vida dos(as) jovens:

Porque en era muito calado e depois que eu comecei a trabalbar com men pai ele até reclamava isso você tem que tratar o cliente bem... Eu chegava na casa do cliente e ficava calado e o Bruno conversava comigo, você não precisa ser conversador, você tem que ser mais solto, espontâneo, conversar com as pessoas, um bom dia, uma boa tarde, um sorriso. Ai eu... pelo fato do Bruno me aconselhar muito até hoje, me ajudou a desenvolver mais, me levou pra palestra que ele ia. O Bruno me ajudou bastante nisso, (Felipe)

Diante da análise, constatamos que as experiências desses(as) jovens têm se constituído a partir dos aprendizados construídos por eles e elas na relação com os (as) oficineiros (as) do FV!. Aprendizados esses que envolvem valores e tomadas de decisões para além da violência e da criminalidade, o que confirma a execução do Programa, neste CPC, como um território protetivo e que se configura como um espaço para acolher as demandas e as aspirações desses(as) jovens.

\section{CONSIDERACְ̃̃ES FINAIS}

Para os(as) jovens deste estudo, participantes do Fica Vivo!, o Programa tem cumprido a função protetiva naquele território, além de propiciar experiências educativas, que se revestem de significado, levandoos(as) a se mobilizarem para participar das atividades no Programa.

Constata-se uma dimensão educativa no que tange à relação oficineiro(a) e jovem. As aprendizagens construídas pelo(a) jovem a partir dos ensinamentos do oficineiro(a) são socializadas com outros(as) jovens, e fazem sentido para a vida deles(as), o que pode refletir no uso que eles(as) fazem dos territórios.

O Fica Vivo!, se mostrou como uma das únicas possibilidades de práticas de Esporte, Cultura e Lazer para os jovens que participam das Oficinas. O Programa também foi apontado por eles(as) como espaço para se preparar para a inserção no mercado de trabalho, com orientação para as entrevistas de emprego e para a elaboração de currículos, e ampliou o acesso à cidade via Projetos de Circulação.

A investigação aponta que o território do trabalho se entrelaça com o da escola, com a interrupção de trajetórias escolares interceptadas pela necessidade de opção pelo trabalho. Apesar disso, os(as) jovens têm vontade de voltar a estudar, aspiração que também se vincula à melhoria das condições de inserção no mercado de trabalho. Mesmo em territórios vulneráveis, os(as) jovens constroem 
possibilidades de vida, configuram territórios, imprimem neles suas marcas - como no FV! -, e acreditam em possibilidades - "um dia vai chiar, um dia vai dar certo moço, é só ter fé vai dar certo" (Augusto).

São esses aspectos referenciados pelos(as) jovens que nos fazem compreender como eles vivem a sua condição juvenil naquele território, que guarda as marcas da vulnerabilidade, das desigualdades educacionais e raciais, do encontro com a violência, mas também das suas aspirações e desejos.

Cabe refletir, ainda, que a Política Estadual de Prevenção Social à Criminalidade do Estado de Minas Gerais - que abarca o FV!, cujo foco de atenção é a vulnerabilidade juvenil pelo viés da proteção social e da intervenção estratégica - não está inclusa na pasta de políticas de juventude do Governo de Minas Gerais e, sim, na de segurança pública. Esse é um aspecto preocupante, pois as ações protetivas e educadoras em territórios marcados pela violência e vulnerabilidade juvenil, não podem ser reduzidas a um problema de segurança pública, posto que não se pode ignorar a condição e a situação juvenil, e as intrincadas relações que se estabelecem nos territórios marcados pela vulnerabilidade socioespacial e pelos aglomerados urbanos que vivem os embates entre direito, proteção e contenção.

\section{REFERÊNCIAS}

ABRAMOVAY, M.; CASTRO, M. G.; WAISELFISZ, J. J. Juventudes na escola, sentidos e busca: por que frequentam? Brasília-DF: Flacso - Brasil, OEI, MEC, 2015.

ALVES, M. Z.; OLIVEIRA, I. Juventudes e territórios: o campo e cidade. Belo Horizonte: Editora UFMG, 2014.

ANDRADE, E. R.; FARAH NETO, M. Juventudes e trajetórias escolares: conquistando o direito à educação. In: ABRAMOVAY, M.; ANDRADE, E. R.; ESTEVES, L. C. G. (org.). Juventudes: outros olhares sobre a diversidade. Brasília: UNESCO: ANPED: MEC, 2007.

CARA, D.; GAUTO, M. Juventudes: percepções e exposição à violência. In: ABRAMOVAY, M.; ANDRADE, E. R.; ESTEVES, L. C. G. (org.). Juventudes: outros olhares sobre a diversidade. Brasília: UNESCO: ANPED: MEC, 2007.

CASTRO, M. G.; ABRAMOVAY, M. Jovens em situação de pobreza, vulnerabilidades sociais e violências. Cadernos de Pesquisa, São Paulo, n. 116, p. 143-176, jul. 2002.

CERQUEIRA, D. et al. Atlas da violência 2017. Rio de Janeiro: IPEA-FBSP, 2017.

CERQUEIRA, D. et al. Atlas da violência 2018. Rio de Janeiro: IPEA-FBSP, 2018.

CHARLOT, B. Da relação com o saber: elementos para uma teoria. Porto Alegre: Artes Médicas, 2000. 
CHARLOT, B. (org.). Os jovens e o saber: perspectivas mundiais. Porto Alegre: Artmed, 2001.

CHARLOT, B. Juventudes sergipanas. Aracaju: UNESCO, 2006. v. I, 304p.

CHARLOT, B. Valores e normas da juventude contemporânea. In: PAIXÃO, L. P.; ZAGO, N. (org.). Sociologia da Educação. Petrópolis, RJ: Vozes, 2007.

CHARLOT, B. A relação com o saber nos meios populares: uma investigação nos liceus profissionais de subúrbio. Tradução Cataria Matos. Porto: Livpsic, 2009.

CORROCHANO, M. C. Jovens no Ensino Médio: qual o lugar do trabalho? In: DAYRELL, J.; CARRANO, P.; MAIA, C. L. (org.). Juventude e Ensino Médio. Belo Horizonte: Editora UFMG, 2014.

DAYRELL, J. O jovem como sujeito social. In: Revista Brasileira de Educação, BeloHorizonte, p. 40-52, set./out./nov./dez. 2003. Disponível em <http://www.scielo.br/pdf/ rbedu/n24/n24a04.pdf. >. Acesso em: 02 out. 2014.

DAYRELL, J.(org.). Por uma pedagogia das juventudes: experiências educativas do Observatório da Juventude da UFMG. Belo Horizonte: Mazza, 2016.

DAYRELL, J.; CARVALHO, L. D.; GEBER, S. Os jovens educadores em um contexto de educação integral. In: MOLL, J. et al. Caminhos da educação integral no Brasil: direito a outros tempos e espaços educativos. Porto Alegre: Penso, 2012.

DAYRELL, J.; PAULA, S. G. de. Situação juvenil e formação de professores: diálogo possível? Revista Brasileira de Pesquisa sobre Formação Docente, Belo-Horizonte, v. 03, n. 04, p. 33-53, jan./jul. 2011. Acesso em: 12 de ago. 2016.

GOMES, N. L.; LABORNE, A. A. de P.. Pedagogia da crueldade: racismo e extermínio da juventude negra. Educação em Revista, Belo-Horizonte, v. 34, 2018. e197406,

HAESBAERT, R. O mito da desterritorialização: o “fim dos territórios” à multiterritorialidade. Rio de Janeiro: Bertrand Brasil, 2006.

HAESBAERT, R. Dos múltiplos territórios à multiterritorialidade. GEOgraphia, Rio de Janeiro, ano IX, n. 17, 2007.

HAESBAERT, R. Hibridismo, mobilidade e multiterritorialidade numa perspectiva geográfico-cultural integradora. In: SERPA, A.(org.). Espaços culturais: vivências, imaginações e representações [online]. Salvador: EDUFBA, 2008.

HAESBAERT, R. Viver no limite: território e multi/transterritorialidade em tempos de insegurança e contenção. Rio de Janeiro: Bertrand Brasil, 2014.

INTERNATIONAL LABOUR OFFICE. Global Employment Trends for Youth 2017: Paths to a better working future. Geneva: ILO, 2017.

INSTITUTO NACIONAL DE ESTUDOS E PESQUISAS EDUCACIONAIS ANÍSIO TEIXEIRA (INEP). Censo Escolar da Educação Básica 2016: notas estatísticas. Brasília, DF: INEP, 2017.

LEÃO, G.; NONATO, S. Juventude e trabalho. Belo Horizonte: Editora UFMG, 2014. 
MELO, D. L. B. de; CANO, I. (org.). Índice de homicídios na adolescência: IHA 2009-2010. Rio de Janeiro: Observatório de Favelas, 2012.

MELO, D. L. B. de; CANO, I. (org.). Índice de homicídios na adolescência: IHA 2012. Rio de Janeiro: Observatório de Favelas, 2014.

MINAS GERAIS. Prevenção social à criminalidade: a experiência de Minas Gerais. Belo Horizonte, dezembro de 2009.

MINAS GERAIS. Portfólio da política de prevenção social à criminalidade. Belo Horizonte, 2015.

MINAS GERAIS. Guia de orientações para execução do trabalho. Belo Horizonte, 2016a.

MINAS GERAIS. Instrução no 3.03.20/2016- CG. Grupo Especial de Policiamento em Área de Risco. Belo Horizonte, 2016b.

PERALVA, A. O jovem como modelo cultural. Revista Brasileira de Educação. Juventude e contemporaneidade, Rio de Janeiro: ANPED, n. 5-6, maio/dez. 1997.

PNUD: IPEA: FJP. Desenvolvimento humano para além das médias: 2017. Brasília: 2017. Disponível em: http://www.ipea.gov.br/portal/index.php?option=com_ content\&view $=$ article\&id $=30024 /$ Acesso em: 12 fev. 2018.

SANTOS, S.; ISAYAMA, H. F. O lazer na política de prevenção social à criminalidade de Minas Gerais: O Programa Fica Vivo! Revista Brasileira de Ciência e Movimento. Brasília; v. 22, n. 1, p. 58-69.

SAQUET, M. A.; SPOSITO, E. S. (org.). Territórios e territorialidades: teorias, processos e conflitos. São Paulo: Expressão Popular; UNESP. Programa de Pós-Graduação em Geografia, 2008. p. 73-94.

SPOSITO, M. P. A sociabilidade juvenil e a rua: novos conflitos e ação coletiva na cidade. Tempo Social; Rev. Sociol. - USP, S. Paulo, v. 5, n. 1-2, p. 161-178, 1993. (editado em nov. 1994).

UFMG. Observatório da Juventude. Relatório de pesquisa: a exclusão de jovens de 15 a 17 anos no ensino médio no Brasil: desafios e perspectivas. Belo Horizonte, 2013. Disponível em: http://observatoriodajuventude.ufmg.br/publication/pesquisa-unicef-a-exclusao-dejovens-de-15-a-17-anos-no-ensino-medio-no-brasil/ Acesso em: 14 fev. 2018.

VIANA, L. M. Estéticas, experiências e saberes: artes, culturas juvenis e o Ensino Médio. In: DAYRELL, J.; CARRANO, P.; MAIA, C. L. Juventude e Ensino Médio. Belo-Horizonte: Editora UFMG, 2014.

WAISELFISZ, J. J. Mapa da Violência 2013: homicídios e juventude no Brasil. Brasília, 2013a. 96 p.

WAISELFISZ, J. J. Mapa da Violência: mortes matadas por arma de fogo. Brasilia, 2013b. 55 p.

WAISELFISZ, J. J. Mapa da Violência: os jovens do Brasil. Brasília, 2014. 190 p.

WAISELFISZ, J. J. Mapa da Violência: mortes matadas por arma de fogo. Brasília, 2015. 112 p. 


\section{NOTAS}

1 O ponto de exclamação é parte do nome do Programa, assim intitulado por seus idealizadores. Neste texto utilizaremos esta grafia.

2 Projeto aprovado por um Comitê de Ética em Pesquisa sob o número 58280316.1.0000.5157.

3 Espaço físico de referência para o público atendido pela Política de Prevenção à Criminalidade. Cada CPC tem sua área de abrangência de acordo com os Programas ofertados e geridos naquele local.

4 O projeto "Uso do Espaço Público" visava atender uma demanda apresentada pelos moradores sobre o aumento de arboviroses no bairro. Diversas ações foram desenvolvidas com a participação dos (as) jovens: concurso de desenho, arte de Graffiti; apresentação da Oficina de Capoeira em palestras sobre arboviroses organizadas pelo Posto de Saúde do bairro; atividades recreativas e Rodas de Conversa na Quadra Comunitária, de modo a instigar o respeito ao bem público, assim como a preocupação com a limpeza do local para a saúde dos(as) moradores(as).

5 Participação dos jovens das Oficinas de Futsal do CPC Turmalina na Copa SESC.

6 Informação confirmada a partir da análise do "Cadastro de Jovens em Oficina" desenvolvidas pelo CPC Turmalina. Esse cadastro é preenchido a partir do diálogo entre oficineiros(as) e jovens. $\mathrm{O}(\mathrm{A})$ oficineiro(a) registra o que $\mathrm{O}(\mathrm{a})$ jovem declara, inclusive no que tange à raça.

7 Nomes substituídos para preservar a identidade dos sujeitos.

8 Foi feita a transcrição literal das entrevistas, e os excertos discursivos deste artigo respeitam a oralidade.

9 A Organização Internacional do Trabalho (International Labour Office, 2017) destaca que a média de jovens, entre 15 a 24 anos, desempregados no Brasil é o dobro da mundial, e que 30\% dos(as) jovens brasileiros(as), em 2017, não tinham emprego. Nesse período da análise, a OIT revelou que $35 \%$ das pessoas desempregadas no Brasil eram jovens.

10 Os nomes dos(as) oficineiros(as) foram substituídos para preservar a identidade dos sujeitos.

11 O Programa Mais Educação constitui-se como estratégia do Ministério da Educação para indução da construção da agenda de educação integral nas redes estaduais e municipais de ensino, que amplia a jornada escolar nas escolas públicas, para no mínimo sete horas diárias. Nesse Programa, instituído em 2007, os(as) alunos(as) vivenciavam diferentes atividades de esporte, lazer, cultura, dentre outras, no turno ou contraturno escolar, e que eram conduzidas, em sua maioria, por oficineiros. Nesse formato, o PME funcionou até o ano de 2015 e foi substituído, em 2016, pelo Programa Novo Mais Educação, com outro formato. Informações disponíveis em: http://portal.mec.gov.br. Acesso em: 01 mar. 2018.

12 Esse profissional não é contratado em regime da Consolidação das Leis Trabalhistas (CLT). É considerado pelo Programa como um(a) parceiro(a) com inscrição como Microempreendedor Individual (MEI) e recebe, mensalmente, uma remuneração em forma de bolsa. Além de ser responsável por ministrar as Oficinas, ele(a) deve fornecer o lanche em todos os encontros. O valor da bolsa fornecida para o(a) oficineiro(a) deve incluir sua 
organização financeira, de modo a manter os gastos com a Oficina - como, por exemplo, comprar esmaltes para a modalidade manicure; comprar bola para a modalidade Futsal, dentre outras demandas que se fizerem necessárias.

Submetido: $19 / 07 / 2018$

Aprovado: 27/03/2019

Contato:

Ana Lídia Cristo Dias

Rua Raimundo Avelino Filho, 215 - Maria Eugênia

Governador Valadares $|\mathrm{MG}|$ Brasil

CEP 35.058-520 